Revista Monografias Ambientais - REMOA v. 14, 2015, p. 79-91

EDIÇÃO ESPECIAL: PÓS GRADUAÇÃO EM EDUCAÇÃO,

INTERDISCIPLINARIDADE E TRANSVERSALIDADE

- UNIPAMPA - SÃO GABRIEL - RS

REMOA/UFSM

Revista do Centro de Ciências Naturais e Exatas - UFSM, Santa Maria

Monografias Ambientais

\title{
O solo como temática transversal para um trabalho interdisciplinar no sexto ano do ensino fundamental
}

\author{
The solo as cross theme for interdisciplinary work in sixth year primary education \\ Franciéle Rodrigues Furlan Welter ${ }^{1}$, Berenice Soares Bueno ${ }^{2}$
${ }^{1}$ Licenciada em Ciências Biológicas pela UNIPAMPA, Campus de São Gabriel/RS. Pós- graduada em Educação: Interdisciplinaridade e Transversalidade pela Universidade Federal do Pampa - UNIPAMPA.
2 Licenciada em Ciências Biológicas, Especialista em Educação: Interdisciplinaridade e Transversalidade pela Universidade Federal do Pampa - UNIPAMPA. Docente no curso de Ciências Biológicas da UNIPAMPA, Campus de São Gabriel/RS.

\begin{abstract}
Resumo
O solo é um dos elementos naturais que são trabalhados, na maioria das vezes, de forma isolada na disciplina de Ciências no sexto ano do Ensino Fundamental, porém, os professores da Escola Estadual de Ensino Médio Dr. José Sampaio Marques Luz, tiveram a oportunidade de encontrar conteúdos que podem servir de apoio para dar início a uma trajetória em busca da construção de um currículo integrado, capaz de promover a interdisciplinaridade e que tenha significado para os educandos. A atividade interventiva realizada durante a jornada pedagógica da escola, junto aos docentes, teve por objetivo provocar o diálogo interdisciplinar entre professores de uma mesma área curricular para a produção de uma proposta integradora de conteúdos. Os docentes puderam, após palestras dialogadas, criar, por área do conhecimento, propostas de trabalhos inter, multi e pluridisciplinar. Os resultados evidenciaram que, há com certeza, motivação, por parte dos educadores envolvidos neste trabalho em dialogar e iniciar uma (re) construção do currículo. Entretanto, é necessário tempo disponível para tal transformação, que envolve estudo e dedicação. Os participantes da atividade interventiva elaboraram propostas, partindo do tema proposto, e se propuseram a aplicar e dar continuidade no estudo desta metodologia que busca unificar saberes e torná-los mais significativos aos educandos.
\end{abstract}

Palavras-chave: Livro didático. Solo. Interdisciplinaridade. Currículo e Ensino Fundamental.

\begin{abstract}
Soil is one of the natural elements that are worked, for the most part, in isolation in Science discipline in the sixth grade of elementary school, however, the teachers of the High School State School Dr. José Sampaio Marques Luz, had the opportunity to find content that can serve as support to initiate a search path of building an integrated curriculum, able to promote interdisciplinarity and that is meaningful to the students. The interventional activity performed during the teaching day school, with the school teachers, aimed to trigger interdisciplinary dialogue among teachers of the same subject area for the production of an integrated offering of subjects. Teachers could create after dialogued lectures by area of knowledge, proposals for inter work, multilateral and multidisciplinary. The results showed that, there is certainly motivation on the part of educators involved in this work in dialogue and initiate a (re) construction of curriculum. However, it takes time available for such a transformation, involving study and dedication. Participants of interventional activity developed proposals starting from the proposed theme and set out to apply and to continue to study this methodology that seeks to unify knowledge and make them more meaningful to students.
\end{abstract}

Keywords: Textbook. Soil. Interdisciplinary. Curriculum and elementary school. 


\section{Introdução}

O ser humano produz seus próprios meios de existência. Através da tecnologia criou formas de adubar o solo artificialmente, não se senta mais no chão e sim em cadeiras e sofás. Um meio ambiente natural, belo e exuberante foi rodeado por outro meio, totalmente urbano, modificado através do tempo histórico, pela humanidade. A maioria das pessoas trabalha para ter conforto e pouco sabem sobre a origem das matérias primas que compõem as coisas que utilizam diariamente.

Isso aconteceu devido a uma relação que o homem acreditava ter diretamente relacionada à natureza, explorá-la para ter conforto, trabalho, ascensão social, mas, na verdade, essa relação se dá homem-homem, na busca pelo poder.

O problema maior está na intenção de algumas pessoas de dominar tudo, estando intrínseco na sociedade esse egocentrismo. O respeito ao ambiente natural e a intenção de preservá-lo só é levada em conta quando isso pode causar consequências ao próprio homem. São raros os casos de seres humanos que pensam ser o correto viver como se ele fosse parte da natureza e não dominadores dela.

Desta forma, o presente trabalho aborda a utilização do solo, um recurso natural, amplamente explorado pelo homem, bem como o estudo didático deste elemento realizado em sala de aula a luz da análise do livro didático na perspectiva das disciplinas que compõem a matriz curricular do sexto ano no do Ensino Fundamental.

A pesquisa foi realizada na Escola Estadual de Ensino Médio Dr. José Sampaio Marques Luz (EEML), no município de São Gabriel-RS, onde houve uma atividade interventiva durante a jornada pedagógica do corpo docente direcionada ao estudo do solo.

Buscou-se identificar os livros didáticos que abordam assuntos referentes ao tema solo e em que contexto se dá tal abordagem de forma a utilizá-lo como ferramenta de pesquisa para construção do conhecimento interdisciplinar e melhoria do ensino oferecido no sexto ano do Ensino Fundamental.

Partindo da análise dos diferentes discursos em relação ao solo, apresentados nos livros didáticos esperava-se elaborar propostas de trabalho interdisciplinar utilizando o livro como ferramenta de pesquisa por parte dos educandos do sexto ano do Ensino Fundamental.

A interdisciplinaridade propõe uma integração entre duas ou mais disciplinas do currículo escolar. Entretanto, seria utópico, de imediato, pedir uma integração entre todas as disciplinas de uma só vez. Por isso, durante a intervenção realizada na jornada pedagogia, buscou-se uma integração dos componentes curriculares da mesma área do conhecimento.

\section{Contextualizando a escola}

A Escola Estadual Marques Luz possui, aproximadamente, 1200 alunos distribuídos entre Ensino Fundamental, Ensino Médio e Educação de Jovens e Adultos (Fundamental e Médio). Em 2015, há sete turmas de Ensino Fundamental do sexto ao nono ano, sendo duas de sexto ano.

As duas turmas de sexto ano possuem por volta de 60 alunos matriculados que estudam nos turnos da manhã e tarde, estando em sua maioria entre 10 a 14 anos de idade. Os componentes curriculares que fazem parte do currículo dessa turma são: Língua Portuguesa, Língua Espanhola, Língua Inglesa, Educação Física, Ensino Religioso, Arte, Matemática, Ciências, História e Geografia. As duas turmas contam com quinze professores atendendo a todos os componentes curriculares citados. Visto que muitos professores atuam nas disciplinas sem serem formados na área em que lecionam, o livro didático funciona diretamente como ferramenta pedagógica.

\subsection{Livro didático e currículo escolar: contribuições teóricas}

Os livros didáticos são escolhidos a cada três anos, porém, em ciclos alternados e a cada ano o Fundo Nacional do Desenvolvimento da Educação (FNDE) distribui novos livros aos alunos da Educação Básica. 
Segundo informações disponíveis no link do Plano Nacional do Livro Didático (PNLD), o qual se encontra na página do Ministério da Educação (MEC), seu principal objetivo é: subsidiar o trabalho pedagógico dos professores por meio da distribuição de coleções de livros didáticos aos alunos da educação básica.

Neste ano, em todo Rio Grande do Sul, tivemos 560.360 (Quinhentos e sessenta mil e trezentos e sessenta) alunos somente dos anos finais do Ensino Fundamental beneficiados pelo PNLD, segundo os dados estatísticos do FNDE. 1

Estes dados comprovam que o livro didático é amplamente distribuído nas unidades escolares para alunos e professores.

Tal ferramenta, em muitos casos, é o único recurso que o docente tem para desenvolver seus conteúdos em sala de aula. No entanto, os livros são muito abrangentes e atendem, em parte, as especificidades locais. Até mesmo a linguagem utilizada pode dificultar o trabalho docente e a compreensão discente do(s) tema(s) em estudo.

Para que aconteça comunicação, os alunos devem entender a linguagem utilizada. Temos nos livros didáticos, na maioria das vezes, uma linguagem muito rebuscada e de difícil compreensão por parte dos educandos, porém, a comunicação, é essencial para os estudantes entenderem as problemáticas locais e se tornarem cidadãos críticos, atores, protagonistas e não meras tabulas rasas vazias de conhecimento.

No sentido de formar cidadãos críticos o capítulo II, Artigo 32, seção III da Lei de Diretrizes e Bases da Educação Nacional (LDB), descreve os princípios da Educação Básica, citando, entre outras coisas, que o principal objetivo do Ensino Fundamental é de formar cidadãos, mediante algumas ações.

Por sua vez, a formação do cidadão passa pelo currículo vivenciado no ambiente escolar. Considerase pertinente citar o Capítulo II, artigo 26 da LDB, que fala dos currículos da educação básica, inclusive deixa claro, em todos seus incisos, que o currículo deve estar adequado a cada região, e que aspectos relacionados á cultura brasileira devem ser priorizados:

Art. 26- Os currículos do ensino fundamental e médio devem ter uma base nacional comum, a ser complementada, em cada sistema de ensino e estabelecimento escolar, por uma parte diversificada, exigida pelas características regionais e locais da sociedade, da cultura, da economia e da clientela. (LDB, p. 171, grifo meu ${ }^{2}$ )

Partindo desses pressupostos, é necessário, além da adequação do currículo, ferramentas apropriadas e úteis, trabalho em equipe, diálogo, momentos de reflexão, entre outros. Por exemplo, em Língua Portuguesa, ao invés de abordar gramática de forma descontextualizada, o professor pode, algumas vezes, utilizar um texto que aborde temáticas estudadas em outras disciplinas.

\subsection{Interdisciplinaridade - uma proposta metodológica em construção}

Uma palavra comumente citada na LDB é cidadãos, sendo a formação de cidadãos conscientes e conhecedores de seus direitos e deveres uma das diretrizes que devem nortear os conteúdos curriculares. Nas Diretrizes Curriculares Nacionais (DCNs) (BRASIL, 2013, p. 34), está afirmado que “a perspectiva da articulação interdisciplinar é voltada para o desenvolvimento não apenas de conhecimentos, mas também de habilidades, valores e práticas". Portanto, é necessário discutir a respeito dos conteúdos, e vincular ações interdisciplinares nos currículos escolares, pois, na abordagem interdisciplinar, há além de um intercâmbio de conhecimentos e saberes, também a utilização dos mesmos métodos.

\footnotetext{
${ }^{1}$ A tabela com os dados estatísticos por unidade da federação, demonstrando a quantidade de livros impressos distribuídos por estado, nas três etapas da educação básica: Anos Iniciais, Anos Finais e Ensino Médio, está disponível no site do FNDE: http://www.fnde.gov.br/programas/livro-didatico .

${ }^{2}$ A parte diversificada que trata a LDB, refere-se a pelo menos uma língua estrangeira moderna e a componentes como o Seminário Integrado. No sexto ano do Ensino Fundamental da Escola Marques Luz, são utilizadas os estudos das Línguas Inglesa e Espanhola.
} 
As DCNs (BRASIL, 2013, p. 28-29) fazem uma distinção entre as diferentes abordagens curriculares: As disciplinares, as pluridisciplinares, as interdisciplinares e as transdisciplinares, em relação a essas duas últimas abordagens citadas, as diretrizes descrevem respectivamente que:

\begin{abstract}
A interdisciplinaridade pressupõe a transferência de métodos de uma disciplina para outra. Ultrapassa-as, mas sua finalidade inscreve-se no estudo disciplinar. Pela abordagem interdisciplinar ocorre a transversalidade do conhecimento constitutivo de diferentes disciplinas, por meio da ação didático-pedagógica mediada pela pedagogia dos projetos temáticos. Estes facilitam a organização coletiva e cooperativa do trabalho pedagógico, embora sejam ainda recursos que vêm sendo utilizados de modo restrito e, às vezes, equivocados.
A transversalidade é entendida como uma forma de organizar o trabalho didático-pedagógico em que temas, eixos temáticos são integrados às disciplinas, às áreas ditas convencionais de forma a estarem presentes em todas elas. A transversalidade difere-se da interdisciplinaridade e complementam-se; ambas rejeitam a concepção de conhecimento que toma a realidade como algo estável, pronto e acabado.

Nessa assertiva, Ferreira (2010), quando fala do currículo como instrumento de troca de experiências entre os professores, argumenta que:

\begin{abstract}
A formação de professores para a interdisciplinaridade, indicadora de práticas na intervenção educativa, liga-se ao desenvolvimento de competências para 'construir pontes' entre os conteúdos das disciplinas que lecionam, com os de outras disciplinas do projeto curricular da escola, em vista do sujeito da aprendizagem (FERREIRA, 2010 p. 22).
\end{abstract}

Visto que não se tem na escola uma organização do trabalho pedagógico, que propicie a prática interdisciplinar, o currículo, com efetivo planejamento e ação dos docentes, se torna uma ferramenta essencial para abordagens interdisciplinares dos conteúdos. Parece incoerente, mas a interdisciplinaridade não existe sem as disciplinas escolares, ela só existe por que as disciplinas se interrelacionam formando um conhecimento único, amplo e complexo. Para isso, se torna necessário uma mudança significativa na forma como são trabalhadas os conhecimentos próprios de cada componente curricular.

Leonir argumenta que "a perspectiva interdisciplinar não é, portanto, contrária à perspectiva disciplinar, ao contrário, não pode existir sem ela e, mais ainda alimenta-se dela" (1998, p. 47).

É comum ouvir sobre interdisciplinaridade e transversalidade no ambiente escolar, nos planos pedagógicos, no projeto político pedagógico. São conceitos mencionados com frequência e que servem de fundamentação teórica para muitos trabalhos escolares e acadêmicos. Por isso, neste trabalho buscou-se fazer uma reflexão sobre interdisciplinaridade a partir do assunto solo, no sexto ano do Ensino Fundamental.

Serviu como base teórica deste trabalho, principalmente a ideia fundamental sobre interdisciplinaridade abordada por Fazenda (2003), que foi a vanguardista em relação ao estudo da interdisciplinaridade no Brasil.

A interdisciplinaridade surgiu na Europa, mais especificamente na Itália e França e chegou ao Brasil no final da década de 1960, trazida por Ivani Fazenda que seguiu os preceitos de Japiassú. Segundo Ivani Fazenda (1994), os movimentos estudantis dessa época, na Europa, revindicavam a discussão de questões de ordem social, política e econômica da época no currículo escolar, fazendo emergir a interdisciplinaridade.

Não existe uma "receita" para desenvolver a interdisciplinaridade na prática, porém, as metodologias de ensino devem basear-se na troca de saberes e construção de um conhecimento amplo.

O diálogo, citado por Fazenda (2003) como elemento crucial para práticas interdisciplinares e para que ocorra troca de saberes e vivências, também é descrito nas Diretrizes Curriculares Nacionais da Educação Básica (DCNEB): 
conhecimentos", e que "o ensino deve ir além da descrição e constituir nos estudantes a capacidade de analisar, explicar, prever e intervir, objetivos que são mais facilmente alcançáveis se as disciplinas, integradas em áreas de conhecimento, puderem contribuir, cada uma com sua especificidade, para o estudo comum de problemas concretos, ou para o desenvolvimento de projetos de investigação elou de ação". Enfatizam que o currículo deve ter tratamento metodológico que evidencie a interdisciplinaridade e a contextualização (BRASIL, 2013, p. 28. Grifo do autor).

Conhecendo diferentes opiniões e/ou pontos de vista, conseguiremos entender de qual perspectiva os colegas de outras áreas observam e compreendem determinada situação. O respeito ao ponto de vista do outro pode contribuir para tornar a sociedade mais justa e humanitária.

É comum escutarmos que a interdisciplinaridade é um modismo pedagógico, que trata os "conteúdos" de forma superficial, que de nada serve para preparar os alunos para serem aprovados em concursos, Exame Nacional do Ensino Médio (Enem), entre outros. Por isso, é importante saber quais são os níveis em que ocorre a interdisciplinaridade escolar, são eles: Interdisciplinaridade curricular e didática, esses planos fazem funcionar a interdisciplinaridade pedagógica que é a interdisciplinaridade em ação.

[...] três planos de aprendizagem: e disciplina no nível curricular, a interdisciplinaridade no nível didático e a transdisciplinaridade no nível pedagógico (TOCHON, 1990, apud LENOIR, 1998).

Geralmente o tempo para diálogo entre professores é realizado em um dia específico da semana, e muitas vezes esses momentos são utilizados para discutir a indisciplina dos alunos, dificuldades em relação ao aprendizado, infraestrutura da escola, entre outros assuntos. Raramente esses encontros são utilizados para dialogar sobre os conteúdos que estão sendo trabalhados, para propor e/ou discutir formas de facilitar a aprendizagem dos educandos e outras atitudes que solucionariam os problemas levantados.

\section{Marco Metodológico}

A pesquisa de abordagem quali-quantitavia contou com uma atividade interventiva realizada durante a semana da Jornada Pedagógica de Estudos promovida pela escola. A intervenção teve por objetivos promover a formação teórica dos educadores acerca dos temas "Solo e Interdisciplinaridade", bem como oferecer um espaço de discussões e debates capazes de conduzir a construção de uma proposta interdisciplinar a ser aplicada no sexto ano do Ensino Funndamental.

Os dados desta pesquisa foram produzidos a partir da aplicação de um questionário, contendo cinco perguntas fechadas, cujo objetivo era investigar os critérios utilizados na escolha do livro didático pelos professores do sexto ano do Ensino Fundamental, bem como a forma como é utilizada tal ferramenta no dia a dia do professor.

\section{Resultados obtidos}

O questionário foi respondido por onze professores do Ensino Fundamental II, da Escola Marques Luz, sendo que sete destes participaram da escolha do livro didático.

Quando questionados se existia algum critério utilizado durante a escolha do livro didático os educadores tinham como possibilidade de respostas: Coerência entre conteúdo informativo e a realidade local, opção assinalada por seis educadores; "Design" do livro, opção marcada por dois educadores; Exercícios acessíveis e de fácil compreensão, opção indicada por todos os pesquisados.

Os demais critérios apontados como opções eram: Recursos didáticos adicionais, textos com temas atuais abordados na mídia, experimentos acessíveis, textos que estimulem a criticidade dos alunos e manutenção de estreita relação com as diretrizes e propostas curriculares oficiais, sendo que estes critérios foram assinalados por quatro educadores que participaram da pesquisa. 
Quando questionados quanto à frequência que utilizam o livro didático em suas aulas, 75\% (setenta e cinco) dos pesquisados afirmaram que o utilizam em sala de aula, conforme o gráfico abaixo.

Gráfico 1: Número de professores que utilizam o livro didático em suas aulas.

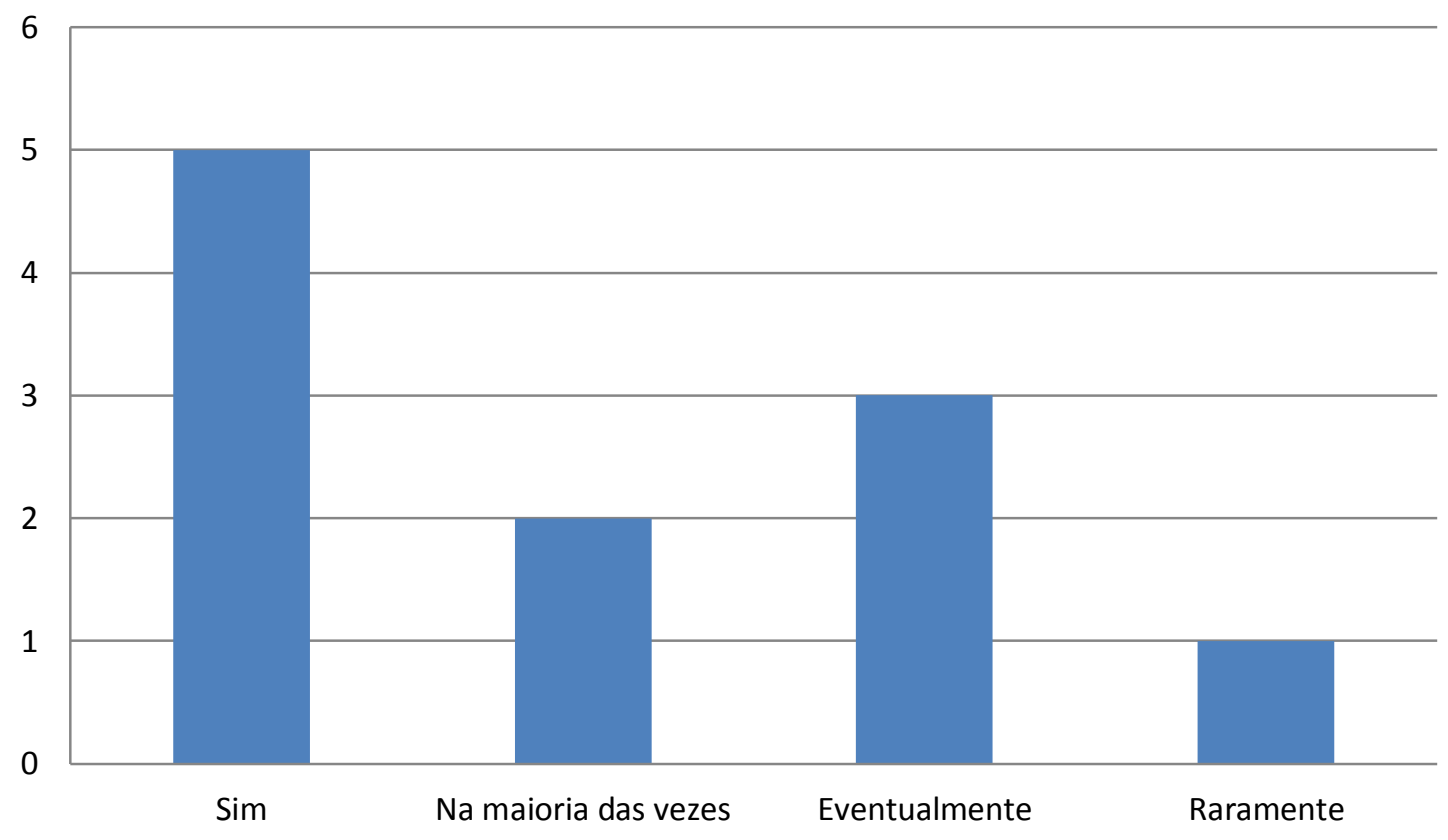

Fonte: Própria autora.

Conforme demonstrado no gráfico os professores utilizam o livro didático para preparar suas aulas, comprovando a importância de analisar essa ferramenta como possível elemento propulsor de práticas docentes significativas e, possivelmente, interdisciplinares.

Gráfico 2 - Número de professores que utilizam o livro didático na preparação de suas aulas.

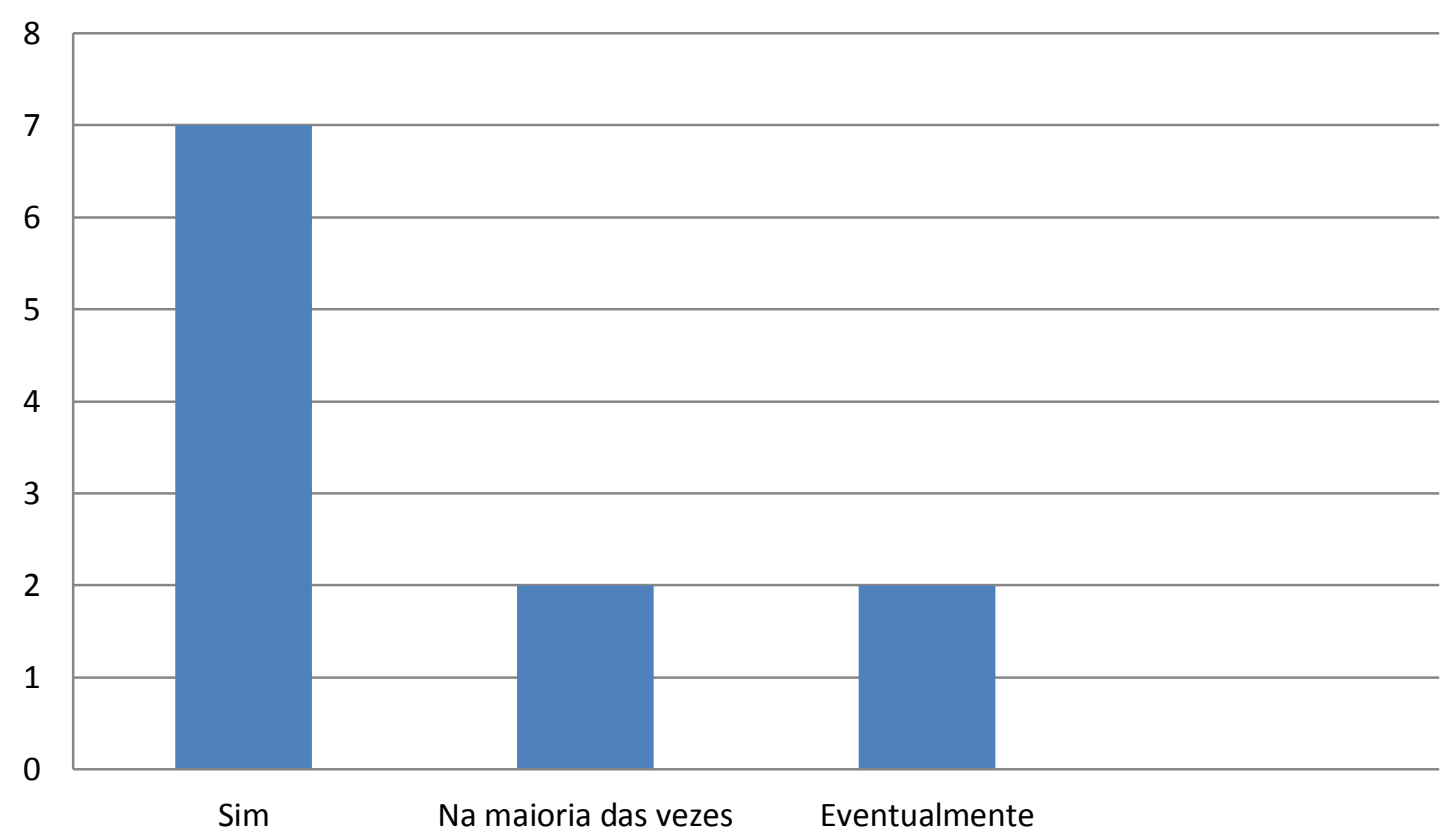

Fonte: Própria autora.

O último questionamento onde foi dada a possibilidade de assinalar mais de uma alternativa indagava: "Em sua opinião, quanto à elaboração do currículo, ele se dá:", as opções disponíveis foram: Após uma reflexão coletiva sobre o Projeto Político Pedagógico (PPP) da escola, apontada por sete 
professores pesquisados; Individualmente, e você tem a autonomia para modificá-lo quando achar necessário, assinalada por dois professores .

Cinco professores responderam que a elaboração do currículo se dá após uma análise da realidade social em que estão inseridos os educandos.

O próximo passo da pesquisa foi a realização da atividade interventiva que contou com docentes das diferentes áreas do conhecimento que trabalham com o sexto ano do Ensino Fundamental, conforme expressa a tabela abaixo:

Tabela 1 - Professores presentes por área do conhecimento que participaram da atividade interventiva.

\begin{tabular}{|c|c|c|}
\hline $\begin{array}{cc}\text { Área } & \text { do } \\
\text { Conhecimento } & \end{array}$ & Disciplina & $\begin{array}{l}\text { Número de professores que } \\
\text { participaram da atividade por } \\
\text { disciplina. }\end{array}$ \\
\hline \multirow[t]{5}{*}{ Linguagens } & $\begin{array}{r}\text { Língua } \\
\text { Portuguesa }\end{array}$ & 2 \\
\hline & Língua Inglesa & 2 \\
\hline & $\begin{array}{r}\text { Língua } \\
\text { Espanhola } \\
\end{array}$ & 1 \\
\hline & Arte & 2 \\
\hline & Educação Física & 2 \\
\hline \multirow[t]{3}{*}{ Ciências Humanas } & História & 2 \\
\hline & Geografia & 2 \\
\hline & Ensino Religioso & 1 \\
\hline Matemática e suas tecnologias & Matemática & 2 \\
\hline
\end{tabular}
Fonte: Própria autora.

É importante salientar que alguns desses professores lecionam em mais de uma disciplina. Esta é a realidade de uma professora que exerce a docência em Arte, Língua Inglesa e Ensino Religioso, porém participou da atividade na área das Linguagens. A disciplina de Ciências não contava com representante tendo em vista que quem exerce a regência desta disciplina é a própria pesquisadora. Inicialmente foi realizada uma abordagem histórica e uma revisão teórica a respeito das legislações vigentes e sua relação com a interdisciplinaridade e transversalidade. A figura 2 registra o momento dessa apresentação.

Figura 2- Histórico e conceitos sobre interdisciplinaridade, transdisciplinaridade e das legislações vigentes que as abordam. 


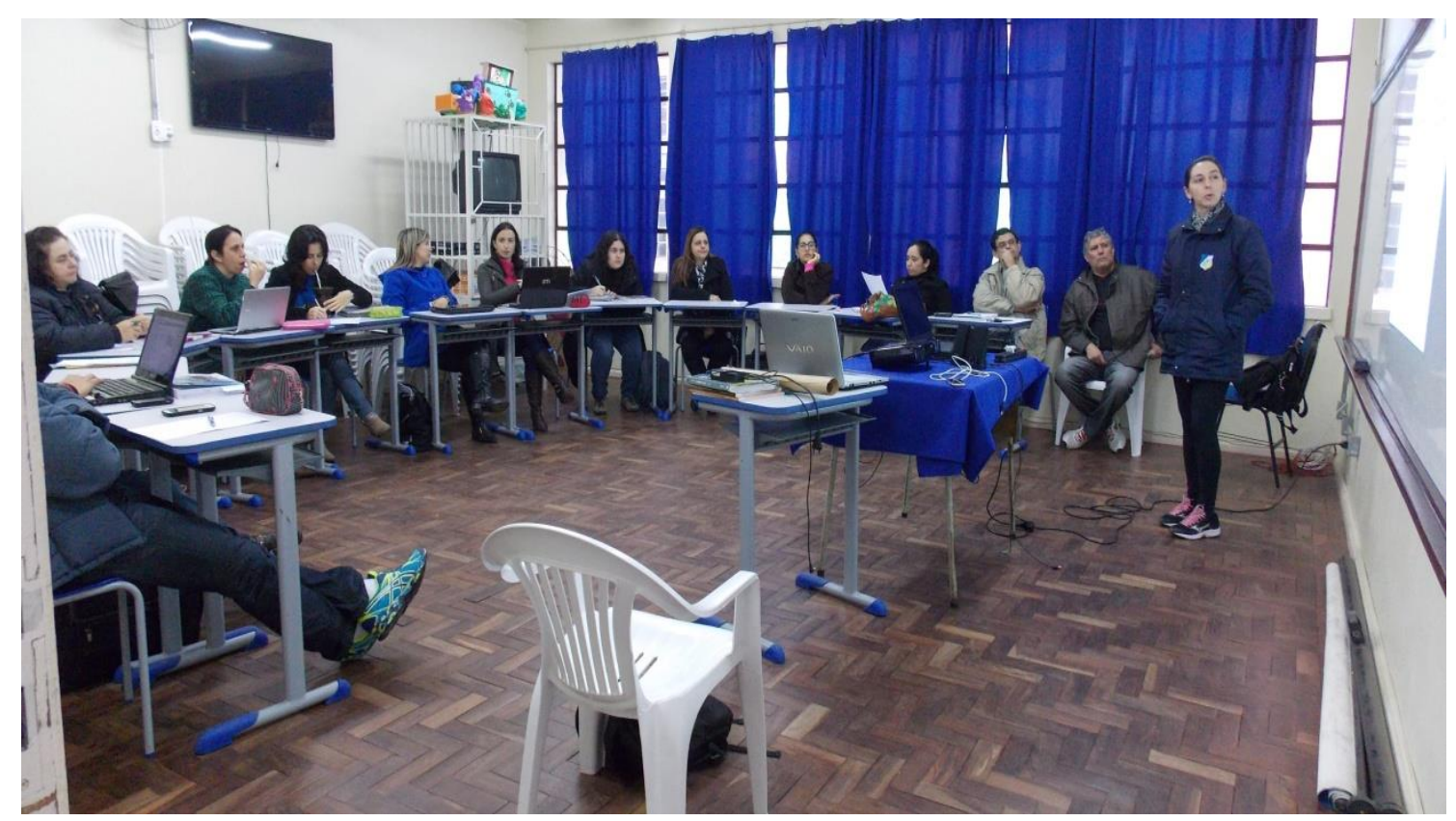

Fonte: Acervo da autora.

Logo após teve-se uma palestra dialogada com a Professora Dr. Mirla Andrade Weber, Engenheira Agrônoma pela UFSM, mestre e doutora em Ciência do Solo pela UFRGS. A palestrante atua na Universidade Federal do Pampa (UNIPAMPA), campus de São Gabriel, nos cursos de Engenharia Florestal, Gestão Ambiental e Ciências Biológicas. A participação da especialista foi de crucial importância, visto que a análise referia-se ao tema solo, e os assuntos abordados por ela ampliou a visão dos professores sobre o tema.

Várias questões sobre o solo foram brevemente comentadas: $\mathrm{O}$ uso de agrotóxicos, microorganismos do solo, erosão, desertificação, o uso excessivo de fertilizantes, entre outras. Essas questões levantadas serviram de base para desenvolver a proposta e aguçou a curiosidade dos participantes, em relação aos conteúdos presentes nos livros didáticos.

Posteriormente, os professores foram divididos por área do conhecimento e desafiados a propor um trabalho interdisciplinar, com a utilização do livro didático como ferramenta de pesquisa, partindo de uma problemática em comum.

Inicialmente os professores analisaram os livros didáticos trazidos por eles e a partir do tema gerador solo criaram uma problemática que orientaria seu trabalho. A escola utiliza livros de apenas uma editora, porém os professores trabalharam com outras obras trazidas por eles para a atividade.

Os professores de Matemática analisaram um livro, e com base no tema solo encontraram alguns conteúdos que poderiam ser trabalhados. A partir do conteúdo de geometria, poderiam desenvolver o estudo das figuras planas, geometria espacial, medidas e equação de $1^{\circ}$ grau para cálculo de nutrientes do solo. O objetivo apresentado pelos professores foi: "Mostrar através do cálculo matemático como um solo mal utilizado reduz a produção, comparado a um bem utilizado." Nesta proposta, os professores tinham um objetivo em comum, entretanto, não criaram uma problemática e abordaram os conteúdos paralelamente ao tema. $\mathrm{O}$ trabalho proposto caracteriza-se por multidisciplinar. Porém, se a partir do objetivo, criarem uma questão que envolva outras áreas pode, se tornar uma atividade pluri ou interdisciplinar. Quando citam no objetivo "através do cálculo matemático" fica claro, que ainda há uma disciplina em destaque, porém eles envolvem a economia, quando falam em produção e também citam solo mal utilizado o que pode envolver conhecimentos relacionados à área das Ciências da Natureza.

Fourez fala sobre a comum confusão entre pluri e multidisciplinaridade: 
A pluridisciplinaridade consiste em tratar uma questão justapondo as contribuições de diversas disciplinas, em função de uma finalidade convencionada entre os parceiros do processo. Este último traço distingue, a nosso ver, a pluridisciplinaridade da multidisciplinaridade (2002. p. 63).

Os professores da área do conhecimento de Ciências Humanas e que trabalham os componentes curriculares de História, Geografia e Ensino Religioso, criaram a partir do tema solo o subtema: "Os tipos de solo e a preservação da cultura material". A problemática criada por elas foi: "Qual é a relevância dos diferentes tipos de solo para a preservação da cultura material produzida pelos homens ao longo da História?". Os conteúdos envolvidos na problemática encontrados no livro didático para subsidiar o estudo foram: Fontes históricas, pré-história, tipos de solos, paisagem e diversidade cultural, conforme figuras 3 e 4 .

Fourez afirma que a "interdisciplinaridade acontece quando há interconexão das disciplinas em função de um contexto particular e de um projeto determinado" (2002, p. 70) e complementa:

As disciplinas são, antes, tratadas, como recursos que, na e pela sua complementaridade, permite conceptualizar, analisar, discutir ou mesmo resolver a problemática envolvida (2002. p.73).

Nesse sentido, o trabalho proposto é interdisciplinar, pois, os professores através dos conhecimentos das diferentes disciplinas responderam uma problemática em comum.

Figura 3- Construção de proposta de trabalho interdisciplinar pelos professores da área das Ciências Humanas.

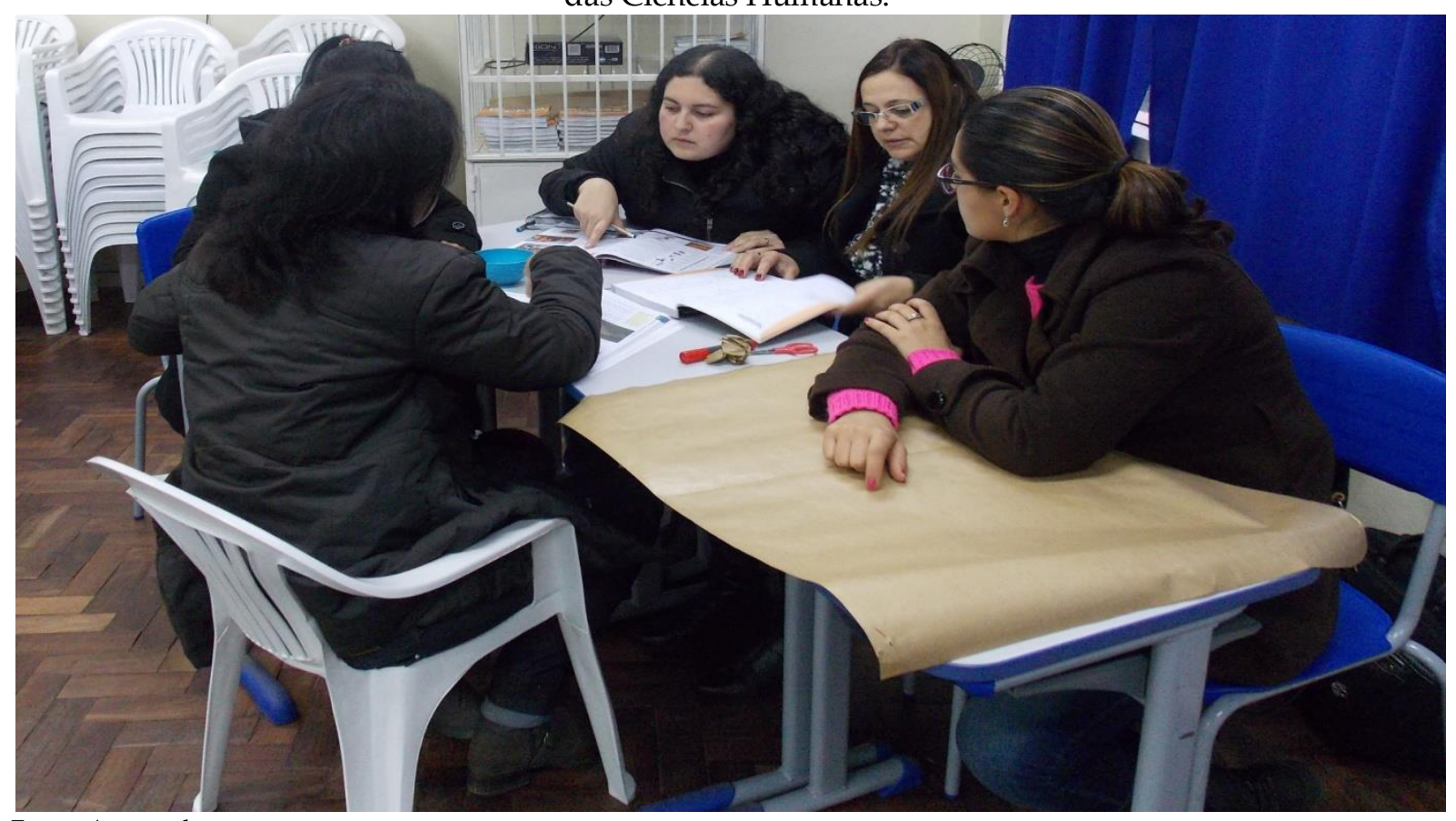

Fonte: Acervo da autora.

Figura 4 - Professor da área das Ciências Humanas apresentando sua proposta de trabalho interdisciplinar. 


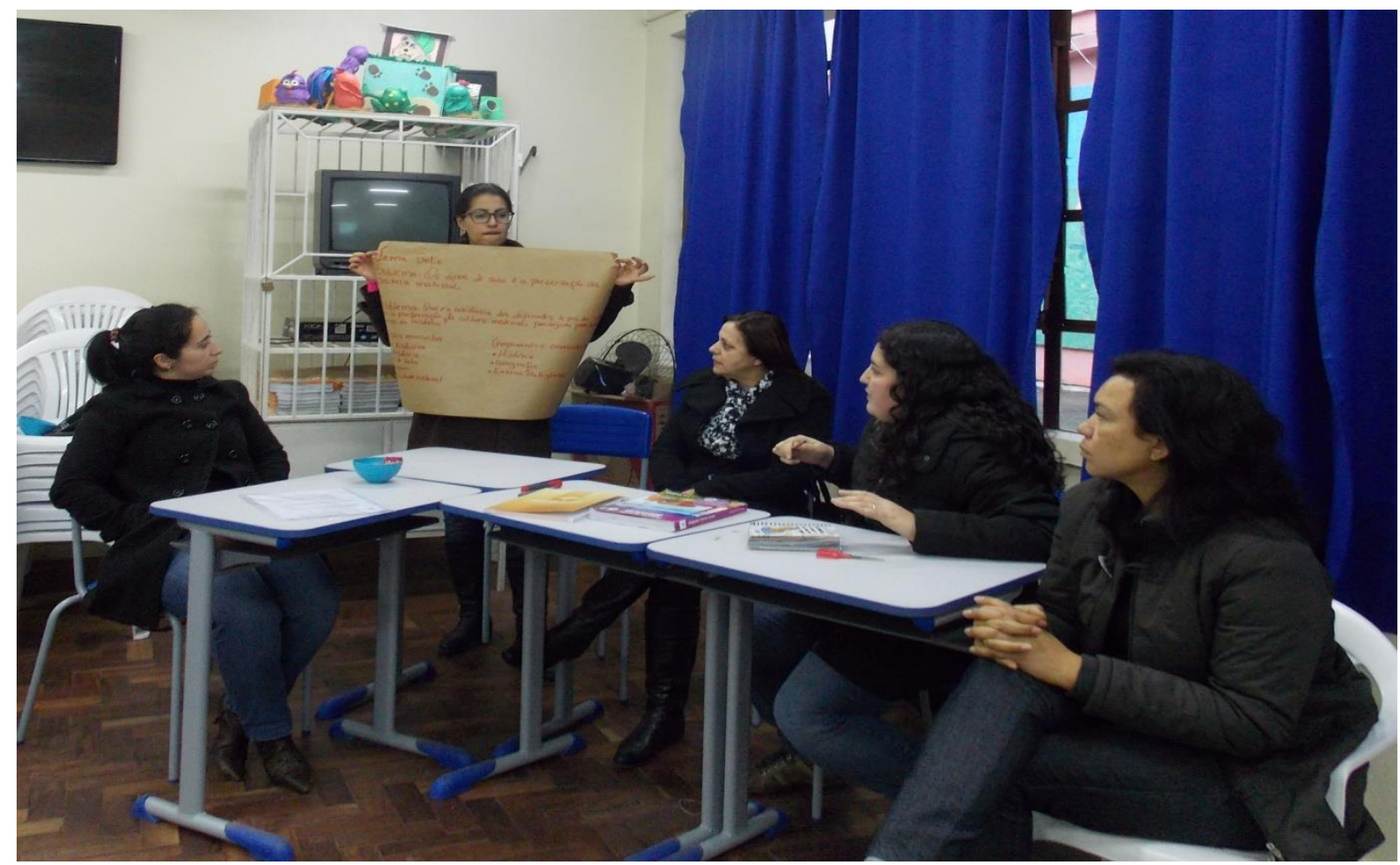

Fonte: Acervo da autora.

Os professores de Língua Portuguesa, Educação Física, Arte, Inglês e Espanhol desenvolveram um trabalho em conjunto a partir do subtema "Você conhece o lugar onde vive?", partindo da seguinte problemática: "Conhecemos onde vivemos na sua íntegra com perspectiva da preservação do solo?". A disciplina de Língua Portuguesa contribuiria com amparo literário e revisão bibliográfica. A disciplina de Língua Inglesa faria a análise de rótulos dos resíduos que fossem encontrados durante uma caminhada. A disciplina de Arte participaria incentivando a ilustração a partir das observações dos alunos. A ação seria realizada durante uma caminhada pelo bairro para conhecer os detalhes e realizar observações, de acordo com proposta dos dois professores de Educação Física. A culminância seria um seminário no qual os alunos apresentariam suas observações e reflexões acerca do que foi observado. No caso desta proposta fica evidente o diálogo entre as disciplinas e, além disso, a realidade é tomada como fonte de coleta e observação de dados o que torna a atividade dinâmica e atraente aos envolvidos.

Lück afirma que:

[...] a interdisciplinaridade se constitui em um processo contínuo e interminável de elaboração do conhecimento, orientado por uma atitude crítica e aberta à realidade, com o objetivo de apreendêla e apreender-se nela, visando muito menos a possibilidade de descrevê-la e muito mais a necessidade de vivê-la plenamente." (2010. p. 50)

Os livros de Língua Portuguesa e Educação Física não foram utilizados para análise, o primeiro componente curricular não trata do conceito solo e o segundo não utiliza livro. Entretanto, os professores participaram da elaboração da proposta, levando em conta os conteúdos estudados no sexto ano do Ensino Fundamental.

Quanto aos dados obtidos a partir da análise dos livros a obra didática de História utilizada pelos professores para a realização da tarefa proposta na intervenção traz um mapa conceitual que fala sobre agricultura, mas não fala sobre solo diretamente. Os outros livros analisados não fazem referência ao tema solo nem mesmo de forma indireta.

Os educadores presentes nesta atividade mostraram-se comprometidos em romper com a hegemonia de umas disciplinas sobre outras e tentar integrar os conteúdos na turma analisada. 


\section{Considerações finais}

O presente trabalho confirmou que a interdisciplinaridade não é uma utopia a ser alcançada na Escola, mas sim uma meta a ser aperfeiçoada com o tempo.

Sempre é possível atingir maiores níveis de interdisciplinaridade. No entanto, é preciso estar consciente dos obstáculos e buscar superá-los, sejam eles, falta de horário para planejamento coletivo, re (significação) dos tempos e espaços escolares entre outros elencados pelo grupo de trabalho que participou desta pesquisa.

Os diálogos realizados durante a atividade interventiva comprovaram que se faz necessário elaborar currículos mais significativos, nos quais as disciplinas abordem temas comuns entre elas nos mesmos momentos, fazendo uso das mesmas metodologias e recursos com vistas à aplicação de propostas mais integradas. Comentários dos professores durante a intervenção atestam a necessidade de uma mudança no currículo, uma (re) construção deste, a partir de problemas sociais e ambientais que fazem parte do contexto sócio-histórico em que está inserida a comunidade escolar.

Os professores envolvidos nessa atividade interventiva, que ganhou uma conotação bastante reflexiva, demonstraram interesse em reformular o currículo e concluíram de forma bastante sinérgica que isso envolve tempo, estudo da realidade em que estão inseridos os educandos e de forma democrática, ou seja, com a participação de toda comunidade escolar.

Para que um projeto interdisciplinar torne-se possível, as pessoas nele envolvidas devem ter vontade para isso. Essa vontade é notável no grupo de professores que atuam no sexto ano do Ensino Fundamental II da Escola Marques Luz.

Foi marcante vivenciar tal momento, pois, os professores colaboraram com seus colegas, ocorreu o diálogo, citado por Ivani Fazenda (2003), e se fortaleceu a importância de momentos de reflexão-ação. A participação de uma especialista em solos ajudou muito na construção das problemáticas e na pesquisa ao livro didático em relação aos conteúdos que se adequavam ao tema solo e a sua problemática.

Os livros didáticos nem sempre contribuem na construção de uma proposta interdisciplinar, mas o interesse dos docentes de trabalhar desta forma e inquestionável, portanto, seria interessante que na construção desta ferramenta os autores, de uma mesma editora, dialogassem e criassem pontes do conhecimento de forma interdisciplinar.

Quanto à atividade proposta por áreas do conhecimento a área da Matemática apresentou uma proposta pertinente que se pensada em conjunto com outras áreas pode fazer uso de conhecimentos e métodos conjuntos.

Por sua vez, as disciplinas das Ciências Humanas estabeleceram bons nexos a partir de uma problemática sendo capazes de utilizar estratégias de pesquisa compartilhadas para superar a perspectiva disciplinar do tema "solo", caminhando na direção da interdisciplinaridade.

Os professores da área das Linguagens criaram uma atividade integrada e dinâmica, porém, não ficou explicito a participação de algumas disciplinas, entretanto, os docentes trabalharam com um tema que partiu da realidade em que todos estão inseridos. Nesse sentido, professor e aluno serão os sujeitos em busca do conhecimento. Os envolvidos ao invés de trabalharem algo abstrato ou descontextualizado, estarão em contato e produzirão com base no que estão vendo e vivenciando.

Convém ressaltar que o diálogo entre os educadores deve acontecer com mais frequência, devendose buscar tempo para troca de ideias e saberes. Os professores precisam reconhecer a importância de formar cidadãos cientes da realidade social e econômica, discutir assuntos coerentes e que tenham significado aos educandos a fim de construir aprendizagens significativas e, se possível, interdisciplinares.

\section{Referências bibliográficas}


BRASIL. Ministério da Educação. Diretrizes Curriculares Nacionais Gerais da Educação Básica. Secretaria da Educação Básica. Secretaria de Educação Continuada, Alfabetização, Diversidade e Inclusão. Brasília: MEC, 2013.

. Ministério da Educação e Cultura. Lei de Diretrizes e base da Educação Nacional - LDB. Centro de documentação do Congresso Nacional. Brasília, DF, 1996.

. MEC. CNE. Parecer $n^{\mathbf{0}} 15$ da Câmara de Educação Básica. Brasília, 1998.

Secretaria de Educação Fundamental. Parâmetros curriculares nacionais: Ciências Naturais. Brasília: MEC /SEF, 1998.

FAZENDA, Ivani C. A. (Org.) Interdisciplinaridade: História, teoria e pesquisa. 11.ed. São Paulo: [s.e.], 2003.

Didática e interdisciplinaridade. Campinas: Papirus, 1998.

FERREIRA; Nali Rosa Silva. Currículo: espaço interdisciplinar de experiências formadoras do professor da escola de educação básica. Publicação Oficial do GEPI - Grupo de Estudos e Pesquisa em Interdisciplinaridade - Educação/Currículo - Linha de Pesquisa: Interdisciplinaridade: PUC/SP. R. Interd., São Paulo, Volume 1, número 0, p.01-83. Out, 2010.

FRACALANZA, Hilário; MEGID Neto, Jorge. O livro didático de ciências: problemas e soluções. Ciência E Educação, v. 9, n. 2, p. 147-157, 2003.

FOUREZ, Gérard. MAINGAIN, Alain. DUFOUR, Barbara. Abordagens didácticas da interdisciplinaridade. Título Original: Approches didactiques de l'interdisciplinarité. Lisboa: Instituto Piaget, 2002.

LENOIR, Y. Didática e interdisciplinaridade: uma complementaridade necessária e incontestável. In: FAZENDA, I. (org.) Didática e interdisciplinaridade. São Paulo: Papirus, 1998.

LÜCK, Heloísa. Pedagogia Interdisciplinar: fundamentos teóricos metodológicos. 17. ed. Petrópolis/RJ: Vozes, 2010.

PLANO NACIONAL DO LIVRO DIDÁTICO/2015, disponível em: <http://www.fnde.gov.br/ programas/livro-didatico/livro-didatico-editais/item/4032-pnld-2015> Acesso em 31/05/2015 às 15h $34 \mathrm{~min}$.

PLANO NACIONAL DO LIVRO DIDÁTICO/ 2015 Histórico, disponível em: <http://www.fnde.gov.br/ programas/livro-didatico/livro-didatico-historico> Acesso em 05/06/2015 às 19h 59min.

SPIASSI; Ariane. Análise de livros didáticos de ciências: um estudo de caso. Revista Trama - Volume 4 - Número 7 - 1o Semestre de 2008 - p. 45 - 54.

\section{Apêndice}


APÊNDICE 1: Questionário aplicado aos professores da Escola Estadual de Ensino Médio Dr. José Sampaio Marques Luz sobre a escolha e utilização do livro didático.

1 Você participou da escolha do livro didático?
( ) $\operatorname{Sim}$
( ) Não

Se a resposta à pergunta anterior foi sim, responda a próxima pergunta. Existe algum critério utilizado durante a escolha do livro didático? Quais são esses critérios?

( ) Coerência entre conteúdo informativo e a realidade local.

( ) “Design" do livro.

( ) Exercícios acessíveis e de fácil compreensão.

( ) Recursos didáticos adicionais.

( ) Textos com temas atuais abordados na mídia.

( ) Experimentos acessíveis.

( ) Textos que estimulem a criticidade dos alunos.

( ) Manutenção de estreita relação com as diretrizes e propostas curriculares oficiais.

( ) Todas as alternativas

( ) Outros. Quais são?

2 Você utiliza o livro didático nas aulas?
( ) Sim
( ) Na maioria das vezes
( ) Eventualmente
( ) Raramente
( ) Não

3 Você utiliza o livro didático no planejamento/preparação das suas aulas?
( ) Sim
( ) Na maioria das vezes
( ) Eventualmente
( ) Raramente
( ) Não

4 Se você utiliza o livro didático no planejamento/preparação das suas aulas, responda a esse questionamento: $\mathrm{O}$ livro didático facilita o planejamento das aulas?
( ) Sim
( ) Na maioria das vezes
( ) Eventualmente
( ) Raramente
( ) Não

$5 \mathrm{Na}$ sua opinião, quanto à elaboração do currículo, ele se dá:

( ) Após uma reflexão coletiva sobre o Plano Político Pedagógico da escola.

( ) Individualmente, e você tem a autonomia para modificá-lo quando achar necessário.

( ) Após uma análise da realidade social em que estão inseridos os educandos. 